Aim of the study: To explore the mechanism of oxidative stress in the development of prostate cancer, here we compared 4-hydroxynonenal (4-HNE)treated LNCaP(hormone-sensitive) and DU145 (hormone insensitive) cells with significant differences in sensitivity to androgen.

Material and methods: The prostate cancer cell line LNCaP and late cell line DU145 were treated with different concentrations of 4-HNE. The cell proliferation, apoptosis and mitochondrial transmembrane potential were detected at different time points, and expression of related molecules in cell proliferation and apoptosis signal pathway was analyzed by Western blot, and the over-expression of glutathione S-transferase (GSTA-4) was used to validate the changes of the effects of 4-HNE on the two kinds of cells.

Results: LNCaP cells showed greater antiproliferative and proapoptotic activities of HNE in a time- and dose-dependent manner corresponding to the activation of p53-mediated intrinsic apoptotic signaling, but JNK activation was not observed. In contrast, HNE-treated DU145 cells showed less apoptosis and proliferation was not inhibited; instead there was sustained activation of JNK, but activation of p53, p-p53, p21, Bax and caspase-3 was not observed. In addition, their effect of induction of apoptosis can be inhibited by overexpression of GSTA-4. Conclusions: These studies suggest that 4-HNE promotes prostate cancer cell apoptosis through the p53 signaling pathway; the differences of sensitivity to 4-HNE in LNCaP and DU145 cells may be related to the androgen sensitivity of prostate cancer cells and the 4-HNE-induced p53-mediated apoptosis signal is regulated by GSTA-4.

Key words: prostate cancer, 4-hydroxynonenal, p53 signal pathway, glutathione S-transferase.

Contemp Oncol (Pozn) 2014; 18 (1): 22-28 DOI: $10.5114 /$ wo. 2014.40456

\section{Comparison of 4-hydroxynonenal- -induced p53-mediated apoptosis in prostate cancer cells LNCaP and DU145}

\author{
Zhi-Gang $\mathrm{Cao}^{1}, \mathrm{Xu} \mathrm{Xu}{ }^{1}$, Ye-Min Xue ${ }^{2}$, Shu-Li Zhao ${ }^{1}$
}

${ }^{1}$ Urology Surgery, Nanjing First Hospital, Nanjing Medical University

${ }^{2}$ Department of Food Science and Nutrition, GinLing College, Nanjing Normal University

\section{Introduction}

With the increase of detection rate of prostate cancer in recent years, an aging population and lifestyle changes have significantly increased the risk of prostate cancer, which has now become a serious threat to elderly men's health in our country [1, 2]. For advanced prostate cancer, androgen deprivation therapy (surgical castration, androgen analogues or estrogen) has been recognized as one of the effective treatments for many years [3, 8]. But after a median time of 18 to 24 months of treatment, many patients with prostate cancer gradually produce hormones of tolerance type for hormone refractory prostate cancer. The pathogenesis of type for hormone refractory prostate cancer remains unclear at present, so there are no effective treatment methods. Many animal experiments show that surgical castration can enhance the oxidative stress reaction in mice prostate tissue, and causes an increase of 4-hydroxynonenal (4-HNE) expression [9]. 4-Hydroxynonenal is a major end product from lipid peroxidation of omega- 6 polyunsaturated fatty acids (PUFA) induced by oxidative stress, playing an important regulatory role in cell differentiation, proliferation and apoptosis and the expression of a multitude of genes including p53 in cells of diverse origin [9-11]. Further study showed that 4-HNE can prompt high expression of mitogen-activated protein kinase (MAPK) and protein kinase B (AKT); the expression of MAPK and AKT were significantly increased in the hormone refractory prostate cancer cells, and the expression was positively correlated with prostate cancer staging and classification [12]. As an important cell signaling molecule, 4-HNE can induce phosphorylation of the androgen receptor for prostate cancer cells, and significantly enhance susceptibility to dihydrotestosterone (DHT), which is involved in the development of prostate cancer. This suggests that 4-HNE is probably involved in the development of prostate cancer and tolerance of androgen deprivation therapy $[9,10]$.

Since generation of 4-HNE has been suggested to be a common denominator in mechanisms of apoptosis caused by diverse forms of oxidative stress $[13,14]$, it is likely that it would also affect the expression and activation of p53. Despite the great amount of data reported in the literature defining the susceptibility of prostate cancer cells to oxidative damage, little is known about the 4-HNE-mediated activation of p53 in prostate cancer models.

In this study, the different influence of 4-HNE on prostate cancer of androgen-dependent (LNCaP cells) and androgen-independent (DU145 cells) or androgen-refractory type has been evaluated to explore its role in the pathogenesis of androgen-refractory prostate cancer. We attempted to study the effects of 4-HNE on the expression and activation of p53 in LNCaP and DU145 cells, focusing on the p53-mediated intrinsic pathway for apoptosis. Glutathione S-transferase A4-4 (GSTA4-4)-mediated metabolism of 4-HNE is one of the major determinants of the intracellular concentration of 4-HNE [15-18]. There- 
fore, we have also examined the possible role of GSTA4-4 in regulation of 4-HNE-induced, p53-mediated apoptosis in prostate cancer cells.

\section{Material and methods}

\section{Materials}

DU145 (androgen-independent prostate cancer cells) and LNCaP (androgen-dependent prostate cancer cells) cells were obtained from the Shanghai Institute of Cell (Shanghai, China). 4-Hydroxynonenal was purchased from MERCK (German chemical company). The cell culture medium RPMI-1640, DMEM, CCK-8 detection kit, Annexin V-fluorescein isothiocyanate (FITC) apoptosis detection kit, propidium iodide (PI), Lipofectamine 2000 transfection reagent and fetal bovine serum were from GIBCO (Shanghai, China). Bradford reagent, bis-acrylamide, and SDS for SDS-PAGE were obtained from Bio-Rad (Hercules, CA). Horseradish peroxidase labeling goat anti-rabbit IgG $(\mathrm{H}+\mathrm{L})$, Horseradish peroxidase labeling goats in mice IgG $(H+L)$, and Western-blotting detection kit were purchased from Cell Signaling Technology Inc (Shanghai, China). pCNA3.1-GSTA4-4 plasmids were constructed and purified by Nanjing Jinsirui Biological Science and Technology Co., LTD (Nanjing, China). Other reagents were purchased from Nanjing Chemical Reagent Co., LTD.

\section{Cells and culture conditions}

Cells were cultured in DMEM (LNCaP) and RPMI 1640 (DU145) supplemented with $10 \%$ fetal calf serum in a humidified incubator at $37^{\circ} \mathrm{C}$ with $5 \% \mathrm{CO}_{2}$. Cell viability after recovery was observed at 2-3 days. This experiment used cells in logarithmic growth phase.

\section{Cell viability assay}

Cells were trypsinized, washed in $1 \times$ PBS, and seeded $\left(100 \mu \mathrm{l} /\right.$ well, approximately $3.5 \times 10^{3}$ cells) into a 96-well plate and left overnight to attach. After $24 \mathrm{~h}$, the cells were treated with concentrations of 0 (control), 20, 40, 60, 80 and $100 \mu \mathrm{M}$ of 4-HNE and were incubated in an incubator at $37^{\circ} \mathrm{C}$ with $5 \% \mathrm{CO}_{2}$ for $24 \mathrm{~h}$ and $48 \mathrm{~h}$, and then $10 \mu \mathrm{l}$ CCK- 8 at added at $37^{\circ} \mathrm{C}$ for $1 \mathrm{~h}$, and the absorbance at 450 $\mathrm{nm}$ was measured by ELISA. The percent inhibition of the treated cells was calculated by the following formula: \% Inhibition $=100-\left(\mathrm{A}_{450} / \mathrm{A}_{450}{ }^{\circ}\right) \times 100\left(\mathrm{~A}_{450}\right.$ is the absorbance of test wells, while $A_{450}^{\circ}$ is the absorbance of control wells). Triplicate experiments were performed in a parallel manner for each concentration point.

\section{Annexin V-FITC/PI analysis}

Detection of apoptosis was conducted using the Annexin V-FITC/PI apoptosis detection kit according to the manufacturer's protocol. Approximately $1-4 \times 10^{5}$ cells of LNCaP and DU-145 cells in 96-well plates at concentrations of 0 , 20,40 and $80 \mu \mathrm{M}$ of $4-\mathrm{HNE}$ were incubated in an incubator at $37^{\circ} \mathrm{C}$ with $5 \% \mathrm{CO}_{2}$ for $24 \mathrm{~h}$. Cells were digested by trypsin and harvested by trypsinization, washed in $1 \times$ PBS and subsequently incubated for $15 \mathrm{~min}$ at room temperature in the dark in $500 \mu \mathrm{l}$ of $1 \times$ binding buffer containing
$5 \mu \mathrm{l}$ of Annexin V-FITC and $5 \mu \mathrm{l}$ of propidium iodide (PI). Afterward, apoptosis was analyzed by a FACScan laser flow cytometer (FACSCalibur, Becton Dickinson, USA) and BD FACSDiva analysis software.

\section{Stable transfection with pCNA3.1 and pCNA3.1-GSTA4-4}

LNCaP and DU145 cells were plated in six-well plates at a density of $5 \times 10^{5}$ cells per $100 \mathrm{~mm}$ Petri dish having $70-80 \%$ confluent cells, and used for the transfection. The cells were transfected with $3 \mu \mathrm{g}$ of either empty vector pCNA3.1 or the target vector pCNA3.1-GSTA4 with the open reading frame (ORF) of the hGSTA4-4 sequence, using Lipofectamine 2000 reagent (Gibco, Shanghai, China) as per the manufacturer's instructions, resulting in the GSTA4-4 high expression cell line DU145-pCNA3.1-GSTA4-4 and LNCaP-pCNA3.1-GSTA4-4, as well as control cell lines DU145-pCNA3.1 and LNCaP-pCNA3.1.

\section{Preparation of cell extracts and Western blot analysis}

Cells were collected, washed with cold PBS and then incubated in $100 \mu \mathrm{l}$ of RIPA lysis buffer $(50 \mathrm{mM}$ Tris- $\mathrm{HCl}$, $\mathrm{pH}$ 7.5; 1\% NP-40; $150 \mathrm{mM} \mathrm{NaCl} ; 1 \mathrm{mg} \mathrm{ml}^{-1}$ leupeptin; $1 \mathrm{mg} \mathrm{ml}^{-1}$ aprotinin; $1 \mathrm{mM} \mathrm{Na}_{3} \mathrm{VO}_{4} ; 1 \mathrm{mM} \mathrm{NaF}$ ) at $4^{\circ} \mathrm{C}$ for 30 min. Cell debris was removed by centrifugation at $12,000 \mathrm{~g}$ for $10 \mathrm{~min}$ at $4^{\circ} \mathrm{C}$. Protein concentrations were determined using a BCA protein content detection kit (Nanjing Keygen Biotech. Co. Ltd, China). Cell extracts were electrophoresed on a $12 \%$ SDS-polyacrylamide gel, and transferred onto nitrocellulose membrane (Roche, Shanghai, China). The blots were blocked at room temperature for $60 \mathrm{~min}$ in fresh blocking buffer (0.1\% Tween 20 in Tris-buffered saline, $\mathrm{pH} 7.4$, containing $5 \%$ nonfat dry milk), and incubated overnight at $4^{\circ} \mathrm{C}$ with the diluted primary antibody, which were made in 5\% nonfat dry milk in Tris-buffered saline (TBS) containing $50 \mathrm{mM} \mathrm{NaF}$ and $0.05 \%$ Tween 20. After three times washing with T-TBS (Tris-buffered saline containing $0.05 \%$ Tween 20), the membrane was incubated with the diluted horseradish peroxidase-conjugated secondary antibody in TBS with 5\% nonfat dry milk at room temperature for $2 \mathrm{~h}$. After washing again with T-TBS, the transferred proteins were incubated with $\mathrm{ECL}$ solution (Nanjing Keygen Biotech. Co. Ltd, Nanjing, China) for 1 min, in accordance with the manufacturer's instructions, and visualized on Hyperfilm ECL film (Nanjing Keygen Biotech. Co. Ltd, China) at room temperature.

\section{Statistical analysis}

All data of at least three independent experiments are expressed as the mean \pm SD, and analyzed by Student's $t$ test. Values of $p<0.05$ were considered to be statistically significant.

\section{Results}

\section{4-Hydroxynonenal causes apoptosis in DU-145 and LNCaP cells}

The efficacy of 4-HNE in inhibiting cell growth was assessed by MTT analysis. The results reported in Table 1 in- 
Table 1. Inhibitory effect of 4-HNE on the cell proliferation of DU145 and LNCaP cells

\begin{tabular}{|c|c|c|c|c|}
\hline \multirow{2}{*}{ 4-HNE $(\mu \mathrm{mol} / \mathrm{l})$} & \multicolumn{2}{|c|}{ DU145 } & \multicolumn{2}{|c|}{ LNCaP } \\
\hline & $24 \mathrm{~h}$ & $48 \mathrm{~h}$ & $24 \mathrm{~h}$ & $48 \mathrm{~h}$ \\
\hline 20 & $0.32 \%$ & $2.73 \%$ & $10.19 \%$ & $12.03 \%$ \\
\hline 40 & $2.93 \%$ & $1.04 \%$ & $19.46 \%$ & $26.77 \%$ \\
\hline 60 & $3.08 \%$ & $1.13 \%$ & $22.81 \%$ & $50.12 \%$ \\
\hline 80 & $2.82 \%$ & $1.49 \%$ & $28.07 \%$ & $61.85 \%$ \\
\hline 100 & $2.15 \%$ & $1.38 \%$ & $34.22 \%$ & $70.45 \%$ \\
\hline
\end{tabular}

Cell proliferation evaluated by MTT assay in DU145 and LNCaP cells untreated or treated with 20,40,60,80 or 100 $\mu M$ 4-HNE. The results shown were the mean of three parallel experiments (triplicate wells) for each concentration point.

dicated that significant differences were revealed between the two models of prostate cancer utilized (DU145 and LNCaP). In particular, HNE inhibited the growth of LNCaP cells, starting at $20 \mu \mathrm{M}$ for $24 \mathrm{~h}$, respectively, and there was dose- and time-dependent inhibition of proliferation by HNE. A significant decrease in the viable cell population, i.e. $70.45 \%$, was observed in cells treated with $100 \mu \mathrm{M}$ of 4-HNE on LNCaP for $48 \mathrm{~h}$. In contrast, in DU145 cells, HNE caused only a slight reduction in cell proliferation starting at $40 \mu \mathrm{M}$ for $24 \mathrm{~h}$ without statistical significance; even if exposed to $100 \mu \mathrm{M}$ HNE $(P>0.05)$, DU145 manifested a relative resistance to supra-physiological concentrations of 4-HNE toxicity. 4-Hydroxynonenal-induced apoptosis in DU145 and LNCaP cells was further analyzed by flow cytometry. As the results in Figure 1 show, after treatment of $\mathrm{LNCaP}$ cells with different concentrations of 4-HNE ranging from 20 to $80 \mu \mathrm{M}$ for $24 \mathrm{~h}$, the late apoptotic or necrotic cells increased from $16.5 \%$ to $48.2 \%$ in LNCaP cells, and from $17.2 \%$ to $22.8 \%$ in DU145 cells in a dose-dependent manner, indicating that
DU145 cells are more resistant to 4-HNE toxicity compared to the more susceptible LNCaP cells.

\section{4-Hydroxynonenal activates apoptotic signaling in LNCaP cells}

Numerous studies have shown that 4-HNE in many different cell types has the effect of inducing cell apoptosis [19-25]. P53 is an important gene involved in internal cell apoptosis signaling pathways. Based on these results, 4-HNE concentrations of 0-40 $\mu \mathrm{M}$ were used to examine its effect on apoptotic signaling in LNCaP and DU145 cells. Results presented in Figure $2 \mathrm{~A}$ showed that within the 0-40 $\mu \mathrm{M}$ range, 4-HNE caused a dose-dependent increase in p-p53, p21, Bax and caspase-3 in LNCaP corresponding p53 protein which was not changed in LNCaP cells, but an effect of 4-HNE-induced activation of p53, p-p53, p21, Bax and caspase- 3 was not observed in DU-145 cells treated with 4-HNE (Fig. 2B). These results showed that activation of p53-mediated intrinsic apoptotic signaling occurred in

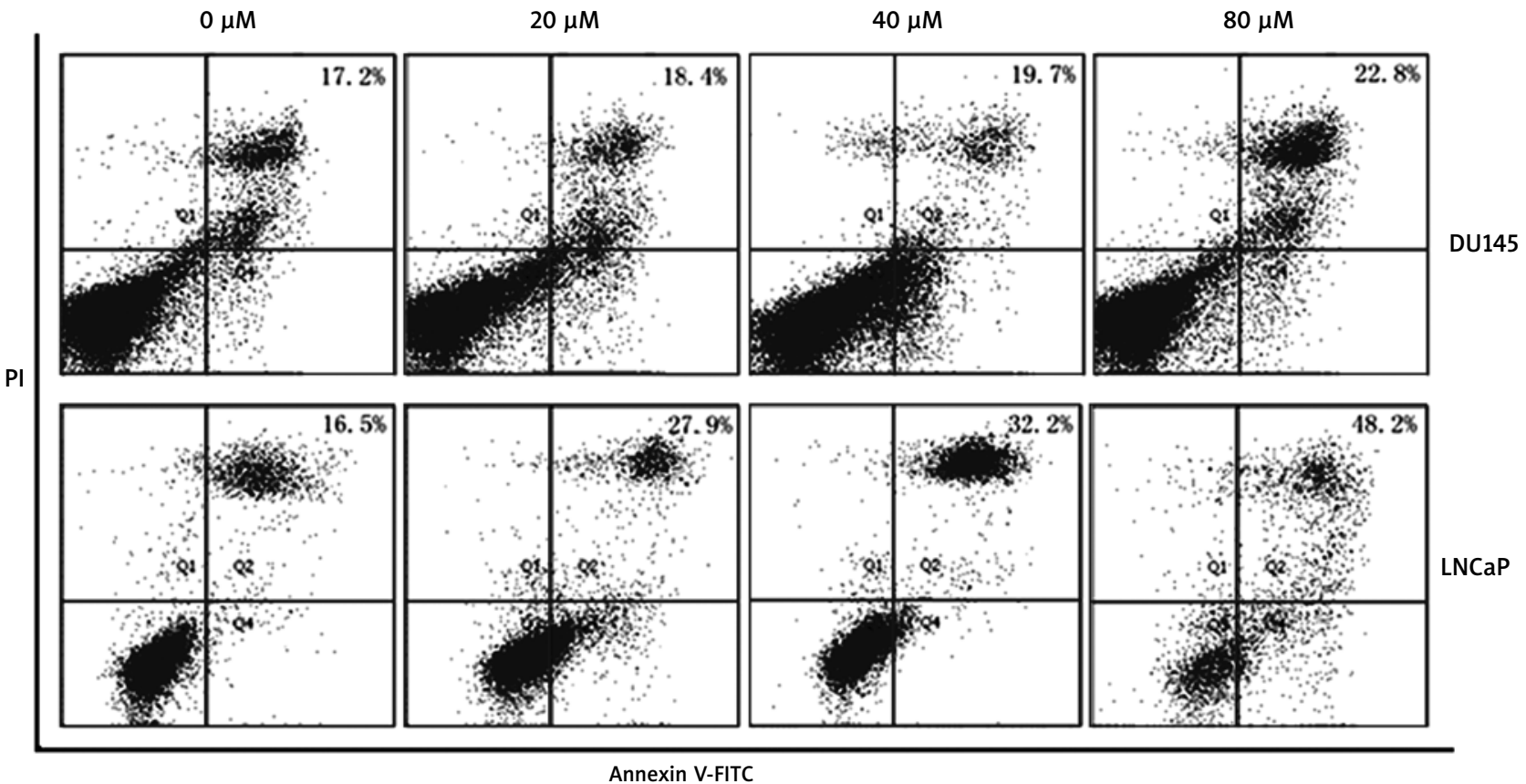

Fig. 1. Effects of 4-HNE on DU145 and LNCaP cell apoptosis analyzed by flow cytometry with Annexin V-FITC, PI staining, and TUNEL assay. Annexin V-FITC in conjunction with PI staining was used to distinguish early apoptotic from late apoptotic or necrotic cells. Fluorescence intensity for Annexin V-FITC is plotted on the x-axis, and PI is plotted on the $y$-axis 
A
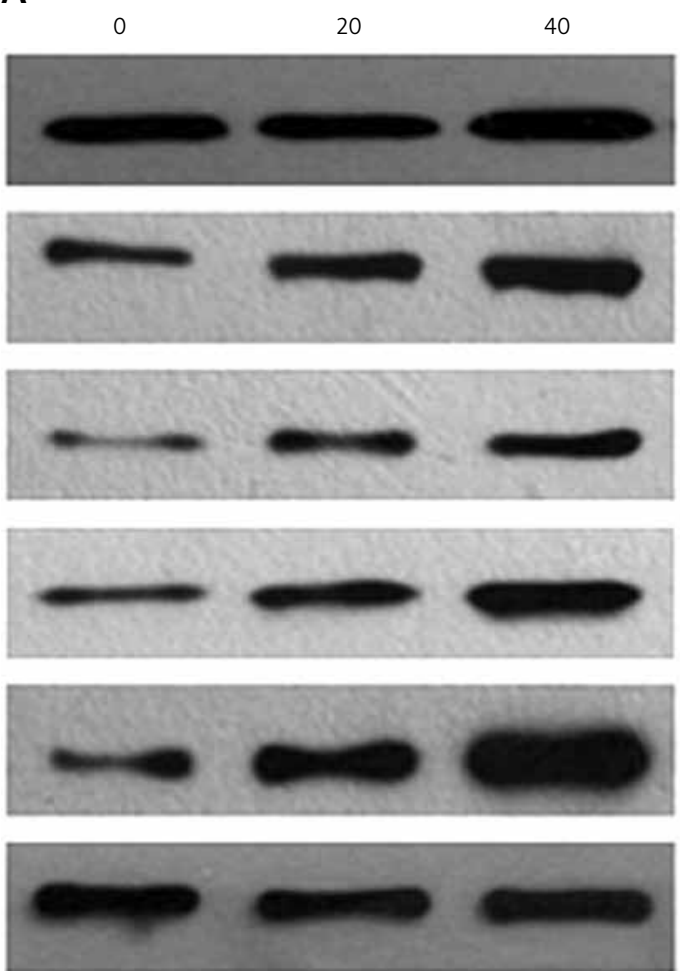

B 4-HNE $(\mu \mathrm{M})$

P53

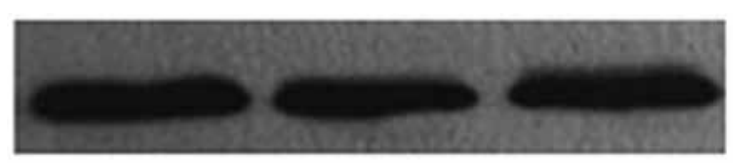

p-P53

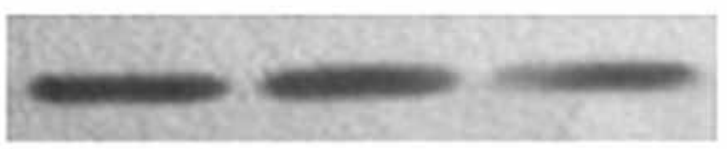

P21

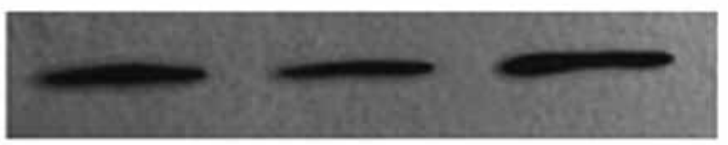

Bax

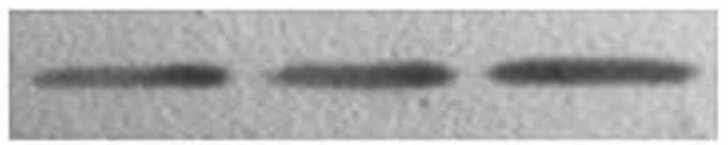

Capase-3

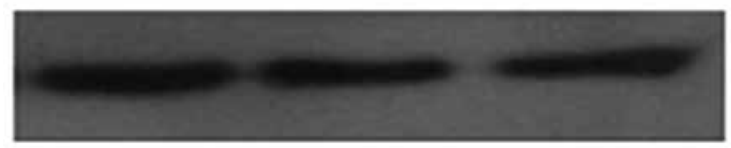

GAPDH

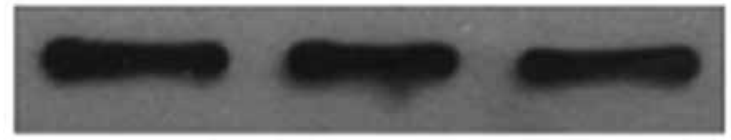

Fig. 2. Effect of 4-HNE on p53-mediated intrinsic apoptotic pathway in LNCaP (A) and DU145 (B). DU145 and LNCaP cells were treated with different concentrations of $4-\mathrm{HNE}(0-40 \mu \mathrm{M})$ for $24 \mathrm{~h}$ at $37^{\circ} \mathrm{C}$, respectively. Total protein lysates were collected as described in the Materials and methods section. The lysates were analyzed by Western blotting for p53, p-p53 (Ser15), p21, JNK, Bax and caspase-3. GAPDH was used as a loading control

LNCaP rather than DU145 cells when exposed to 4-HNE, exhibiting significant differences between DU145 and LNCaP cells. Further studies are needed to evaluate the difference between LNCaP and DU145 cells s in 4-HNE-induced apoptosis in the p53-mediated pathway.

\section{4-Hydroxynonenal activates JNK signaling pathway in LNCaP and DU-145 cells}

A rise in intracellular levels of 4-HNE is a common occurrence when cells are exposed to stressors such as oxidant chemicals, UV radiation and heat shock, and sustained activation of JNK occurs during stress-induced apoptosis in many different cell types [19, 25-27]. The JNK activation is through its phosphorylation on Ser and Thr residues within its $\mathrm{N}$ and C-terminal regions. Therefore, we examined the phosphorylation status of JNK in 4-HNE-treated DU145 and LNCaP cells using the anti-phospho-antibody which specifically detects phosphorylated JNK. As shown in Figure 3B, 4-HNE caused a dose-dependent increase in the phosphorylation of JNK in DU145 cells, but JNK activation (phosphorylation) was not observed in LNCaP cells treated with 4-HNE (Fig. 3A). These results showed that sustained activation of JNK occurred in DU145 rather than LNCaP cells exposed to 4-HNE.

\section{Over-expression of hGSTA4-4 inhibits 4-HNE-induced apoptosis}

During stress conditions causing lipid peroxidation (LPO), the cells with induced GST isozymes have an en- hanced capability to lower 4-HNE and are resistant to apoptosis caused by various oxidants [19, 28, 29]. Therefore, we studied the effect of over-expression of GSTA4 in DU145 and LNCaP cells on 4-HNE-induced apoptotic signaling. Firstly, DU145 and LNCaP cells were stably transfected with hGSTA4-4 and over expression of hGSTA4 protein was confirmed by the results of Western blot analysis (Fig. 4A). Glutathione S-transferase activity for 4-HNE was found to be enhanced in hGSTA4-4 transfected cells along with the expected decrease in the constitutive 4-HNE levels (data not shown). The extent of 4-HNE-induced apoptosis was compared in the empty vector pCNA3.1 and pCNA3.1-GSTA4-4 transfected cells by assessing the activation of caspase-3 in 4-HNE-treated LNCaP cells and JNK and p-JNK in 4-HNE-treated DU145. As shown in Figure 4B, the caspase-3 and p-JNK component activated by 4-HNE was significantly suppressed in hGSTA4-4 transfected cells as compared to that with pCNA3.1-transfected cells. These results demonstrate that the hGSTA4-4 over-expressing cells have an enhanced anti-apoptosis capability, suggesting a regulatory role of GSTA4-4 in p53-mediated, 4-HNE-induced apoptosis.

\section{Discussion}

Prostate cancer is a disease associated with aging. Also commonly associated with increasing age is a shift in the prooxidant-antioxidant balance of many tissues toward a more oxidative state, i.e., increased oxidative stress [30]. Risk factors for prostate cancer and the relationship be- 
A
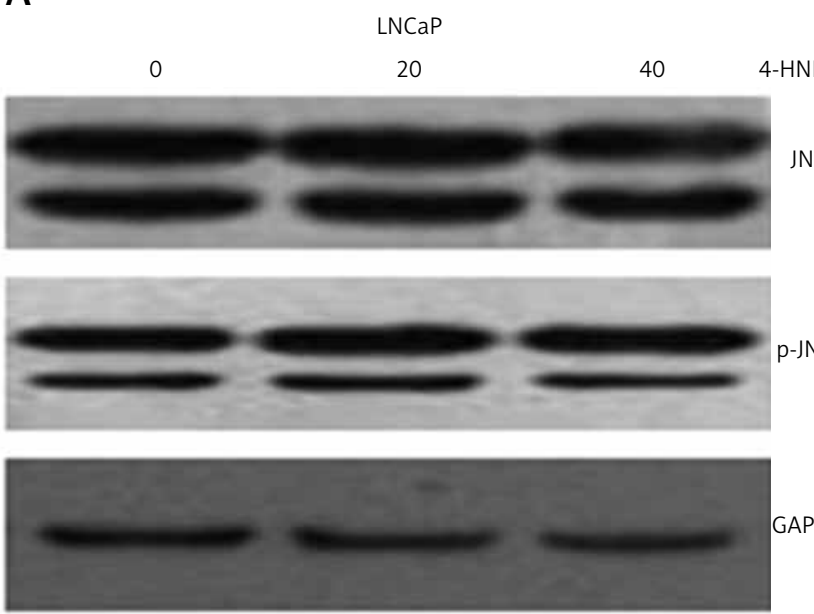

$\begin{array}{lll}\text { 4-HNE }(\mu M) & 0 & 20\end{array}$

40

JNK

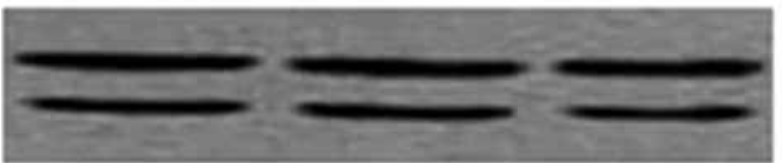

-JNK

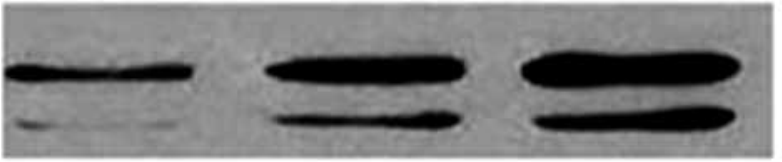

APDH

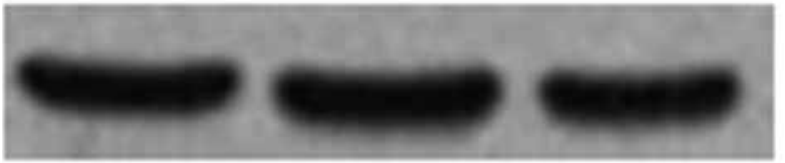

Fig. 3. Effect of 4-HNE on phosphorylation of JNK in LNCaP (A) and DU145 cells (B): LNCaP and DU145 cells were treated with different concentrations of $4-\mathrm{HNE}(0-40 \mu \mathrm{M})$ for $24 \mathrm{~h}$ at $37^{\circ} \mathrm{C}$. The cells were scraped, collected and then washed with ice cold PBS, and the cell lysates were prepared as described in the Materials and methods section. The cell extracts ( $50 \mu \mathrm{g}$ of protein) were subjected to Western blot analyses using anti-JNK and anti-pJNK antibodies. GAPDH was used as a loading control

A

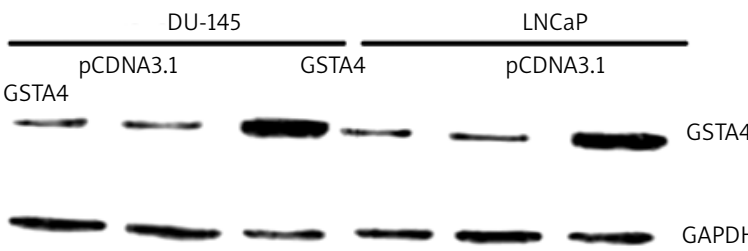

B

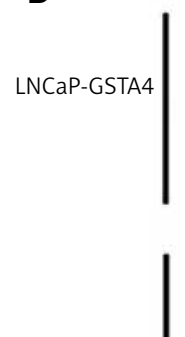

DU245-GSTA4

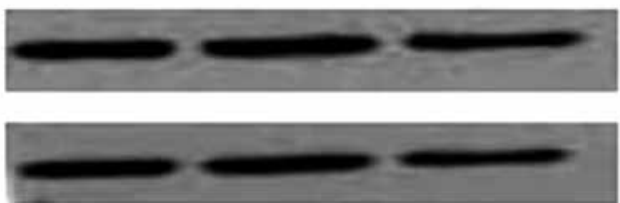

apase3
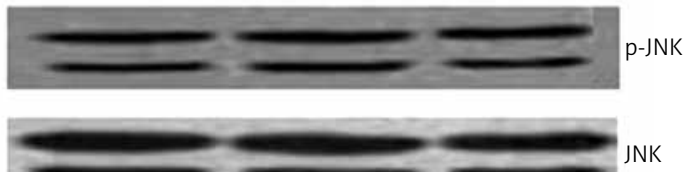

Fig. 4. Effect of hGSTA4 transfection on 4-HNE-induced apoptosis. (A) Western blot analysis shows the expression of hGSTA4-4 in the hGSTA4-4 transfected DU145 and LNCaP cells (A), or treated with different concentrations of 4-HNE $(0-40 \mu \mathrm{M})$ for $24 \mathrm{~h}$ at $37^{\circ} \mathrm{C}$ (B). GAPDH was used as a loading control.

tween oxidative stress have been obtained. Epidemiology, laboratory and clinical studies have clearly proved that oxidative stress has a role in the development of prostate cancer [31-33]. 4-Hydroxynonenal (HNE), as a second messenger of oxidative damage, can cause antiproliferative, prodifferentiative, and proapoptotic effects, modulate cell growth, and affect various signal transduction pathways [19-25, 34-36].

To explore the mechanism of oxidative stress in the development of prostate cancer, the differences in the antiproliferative and proapoptotic effects of 4-HNE in prostate cancer cells were examined using androgen-independent prostate cancer cells such as DU145 or androgen-sensitive prostate cancer cells such as LNCaP. Results from the present study demonstrate that a significant apoptotic effect of 4-HNE was observed on LNCaP cells but not on DU145 cells, and DU145 cells exhibited much more resistance to 4-HNE toxicity than LNCaP cells. Our results are consistent with the study of Piergiorgio et al., who found that 4-HNE induced a strong antiproliferative response in LNCaP cells and only a weak effect in DU145 cells [37]. Although both LNCaP and DU145 cell lines originated from human prostate cancer, they had significant differences in sensitivity to androgen. This indicated that prostate cancer cell apoptosis induced by 4-HNE might be related to the androgen sensitivity of prostate cancer cells.

Consequently, the expression of related molecules in cell proliferation and the apoptosis signal pathway was analyzed by Western blot in 4-HNE induced DU145 and LNCaP cells. In our study, HNE inhibits proliferation of the LNCaP cells with significant apoptosis in a time- and dose-dependent manner corresponding to the activation of p53-mediated intrinsic apoptotic signaling. In contrast, HNE-treated DU145 cells showed less apoptosis and did not show inhibited proliferation; instead there was sustained activation of JNK in DU145 cells exposed to 4-HNE, suggesting that 4-HNE promoted the apoptosis of prostate cancer cells mainly through the p53-mediated signaling 
pathway, and JNK may play different roles in different tumor types. The results reported herein are similar to a previous study showing that JNK activation could be either upstream or downstream of cell death activation, depending on cell type and death-initiating agents [38, 39]. LNCaP (hormone-sensitive) and the late cell line DU145 (hormone insensitive) were prostate cancer cell lines in different development periods. Thus, anti-proliferation and pro-apoptosis of HNE-treated LNCaP cells may be increased by activating the p53 signaling pathway, and those properties of HNE-treated DU145 cells, especially a relative resistance to supra-physiological concentrations of HNE, may be restrained or reduced by activating the JNK signaling pathway.

GSTA4 is 4-HNE reduction control the level of the main enzymes in the cell. In recent years epidemiological studies on different racial types have shown that lower expression of the different categories of GST was positively correlated with prostate cancer risk $[36,40]$. The present study showed that 4-HNE-induced p53 is inhibited by the excessive expression of GSTA4 through accelerating 4-HNE consumption. This indicated that the activation of p53 is 4-HNE's direct role, or its metabolites or degradation products triggered the P53-mediated apoptosis, and 4-HNE can imitate the stress or stress-induced DNA damage in the role of apoptotic signals, suggesting that 4-HNE could cause the stress to induce the p53-mediated intrinsic apoptotic signaling pathway.

In conclusion, our tests have demonstrated that 4-HNE promotes prostate cancer cell apoptosis through the p53 signaling pathway; the differences of sensitivity to 4-HNE in LNCaP and DU145 cells may be related to the androgen sensitivity of prostate cancer cells; and the 4-HNE-induced p53-mediated apoptosis signal is regulated by GSTA-4.

\section{Authors declare no conflict of interests.}

This was work project 200801080, YKK08102 and YKK11125 supported by Nanjing science and technology development projects of China.

\section{References}

1. Haag P, Bektic J, Bartsch G, Klocker H, Eder IE. Androgen receptor down regulation by small interference RNA induces cell growth inhibition in androgen sensitive as well as in androgen independent prostate cancer cells. Steroid Biochem Mol Biol 2005; 96: 251-8.

2. Davarci M, Gokce A, Guven EO, Yalcinkaya FR, Esen H, Sevinc A. Metastatic prostate adenocarcinoma presenting as supraclavicular lymphadenopathy: a report of two cases. Wspolczesna Onkol 2012; 16: 53-5.

3. Zhang SG, Wang YH, Ding Y, Wu Y. Long term survival results in advanced prostate cancer treated with combined androgen. Zhong hua Nan Ke Xue 2005; 11: 770-4.

4. Cieśliński P, Hojan-Osicka M, Antczak A, Kwias Z. Assessment of intraoperative and postoperative complications during implementation of laparoscopic radical prostatectomy in patients with locally advanced prostate cancer. Wspolczesna Onkol 2011; 15: 372-5.

5. Zaborowska M, Szmit S, Szczylik C. Sorafenib in progressive cas trate-resistant prostate cancer. Can we talk about a new therapeutic option? Arch Med Sci 2012; 8: 528-32.

6. Kawalec P, Paszulewicz A, Holko P, Pilc A. Sipuleucel-T immunotherapy for castration-resistant prostate cancer. Arch Med Sc 2012; 8: 767-75.
7. Ziółkowska E, Zarzycka M, Wiśniewski T, Żyromska A. The side effects of hormonal therapy at the patients with carcinoma of prostate cancer. Wspolczesna Onkol 2012; 16: 491-7.

8. Kulik A, Dąbkowski M. Prostate cancer radiotherapy. Wspolczesna Onkol 2011; 15: 317-22.

9. Tam NN, Gao Y, Leung YK, Ho SM. Androgenic regulation of oxidative stress in the rat prostate: involvement of $N A D(P) H$ oxidases and antioxidant defense machinery during prostatic involution and regrowth. Am J Pathol 2003; 163: 2513-22.

10. Usatyuk PV, Natarajan V. Role of mitogen-activated protein kinases in 4-hydroxy-2-nonenal-induced actin remodeling and barrier function in endothelial cells. J Biol Chem 2004; 279: 11789-97.

11. Chen ZH, Saito Y, Yoshida Y, Sekine A, Noguchi N, Niki E. 4-Hydroxynonenal induces adaptive response and enhances PC12 cell tolerance primarily through induction of thioredoxin reductase 1 via activation of Nrf2. J Biol Chem 2005; 280: 41921-7.

12. Rochette-Egly C. Nuclear receptors: integration of multiple signalling pathways through phosphorylation. Cell Signal 2003; 15: 355-66.

13. Cheng JZ, Sharma R, Yang Y, et al. Accelerated metabolism and exclusion of 4-hydroxynonenal through induction of RLIP76 and hGST5.8 is an early adaptive response of cells to heat and oxidative stress. J Biol Chem 2001; 276: 41213-23.

14. Yang Y, Sharma A, Sharma R, Patrick B, Singhal SS, Zimniak P, Awasthi S, Awasthi YC. Cells preconditioned with mild, transient UVA irradiation acquire resistance to oxidative stress and UVA-induced apoptosis: role of 4-hydroxynonenal in UVA-mediated signaling for apoptosis. J Biol Chem 2003; 278: 41380-8.

15. Sharma R, Brown D, Awasthi S, et al. Transfection with 4-hydroxynonenal-metabolizing glutathione S-transferase isozymes leads to phenotypic transformation and immortalization of adherent cells. Eur J Biochem 2004; 271: 1690-701.

16. Patrick B, Li J, Jeyabal PV, et al. Depletion of 4-hydroxynonenal in hGSTA4-transfected HLE B-3 cells results in profound changes in gene expression. Biochem Biophys Res Commun 2005; 334: 42532.

17. Cheng JZ, Singhal SS, Saini M, et al. Effects of mGST A4 transfection on 4-hydroxynonenal-mediated apoptosis and differentiation of K562 human erythroleukemia cells. Arch Biochem Biophys 1999; 372: 29-36.

18. Alshagga MA, Mohamed N, Nazrun Suhid A, Abdel Aziz Ibrahim I, Zulkifli Syed Zakaria S. Frequencies of glutathione s-transferase (GSTM1, GSTM3 AND GSTT1) polymorphisms in a Malaysian population. Arch Med Sci 2011; 7: 572-8.

19. Cheng JZ, Sharma R, Yang Y, et al. Accelerated metabolism and exclusion of 4-hydroxynonenal through induction of RLIP76 and hGST5.8 is an early adaptive response of cells to heat and oxidative stress. J Biol Chem 2001; 276: 41213-23.

20. Awasthi YC, Yang Y, Tiwari NK, Patrick B, Sharma A, Li J, Awasthi S. Regulation of 4-hydroxynonenal-mediated signaling by glutathione S-transferases. Free Radic Biol Med 2004; 37: 607-19.

21. Liu W, Kato M, Akhand AA, et al. 4-Hydroxynonenal induces a cellular redox status-related activation of caspase cascade for apoptotic cell death. J Cell Sci 2000; 113: 635-41.

22. Parola M, Leonarduzzi G, Biasi F, Albano E, Biocca ME, Poli G, Dianzani MU. Increased 4-hydroxynonenal levels in experimental alcoholic liver disease: association of lipid peroxidation with liver fibrogenesis. Hepatology 1992; 16: 1014-21.

23. Li J, Sharma R, Patrick B, et al. Regulation of CD95 (Fas) expression and Fas-mediated apoptotic signaling in HLEB-3 cells by 4-hydroxynonenal. Biochemistry 2006; 45: 12253-64.

24. Laurora S, Tamagno E, Briatore F, et al. 4-Hydroxynonenal modulation of p53 family gene expression in the SK-N-BE neuroblastoma cell line. Free Radic Biol Med 2005; 38: 215-25.

25. Yang Y, Sharma A, Sharma R, Patrick B, Singhal SS, Zimniak P, Awasthi S, Awasthi YC. Cells preconditioned with mild, transient UVA irradiation acquire resistance to oxidative stress and UVA-induced apoptosis: role of 4-hydroxynonenal in UVA-mediated signaling for apoptosis. J Biol Chem 2003; 278: 41380-8.

26. Uchida K, Shiraishi M, Naito Y, Torii Y, Nakamura Y, Osawa T. Activation of stress signaling pathways by the end product of lipid peroxidation. J Biol Chem 1999; 274: 2234-42. 
27. Biasi F, Vizio B, Mascia C, Gaia E, Zarkovic N, Chiarpotto E, Leonarduzzi G, Poli G. C-Jun N-terminal kinase upregulation as a key event in the proapoptotic interaction between transforming growth factor-beta1 and 4-hydroxynonenal in colon mucosa. Free Radic Biol Med 2006; 41: 443-54.

28. Nanji AA, Zhao S, Sadrzadeh SM, Dannenberg AJ, Tahan SR, Waxman DJ. Markedly enhanced cytochrome P450 2E1 induction and lipid peroxidation is associated with severe liver injury in fish oil-ethanol-fed rats. Alcohol Clin Exp Res 1994; 18: 1280-5.

29. Siliciano JD, Canman CE, Taya Y, Sakaguchi K, Appella E, Kastan MB. DNA damage induces phosphorylation of the amino terminus of p53. Genes Dev 1997; 11: 3471-81.

30. Ripple MO, Henry WF, Rago RP, Wilding G. Prooxidant-antioxidant shift induced by androgen treatment of human prostate carcinoma cells. J Natl Cancer Inst 1997; 89(1):40-48

31. Fleshner NE, Klotz LH. Diet, androgens, oxidative stress and prostate cancer susceptibility. Cancer Metastasis Rev 1998-1999; 17: 325-30.

32. Fair WR, Fleshner NE, Heston W. Cancer of the prostate: a nutritional disease. Urology 1997; 50: 840-8.

33. Pienta KJ, Esper PS. Risk factors for prostate cancer. Ann Intern Med 1993; 118: 793-803.

34. Yang Y, Sharma R, Sharma A, Awasthi S, Awasthi YC. Lipid peroxidation and cell cycle signaling: 4-hydroxynonenal, a key molecule in stress mediated signaling. Acta Biochim Pol 2003; 50: 319-36.

35. Jacobs AT, Marnett LJ. HSF1-mediated BAG3 expression attenuates apoptosis in 4-hydroxynonenal-treated colon cancer cells via stabilization of anti-apoptotic Bcl-2 proteins. J Biol Chem 2009; 284: 9176-83.

36. Sharma A, Sharma R, Chaudhary P, et al. 4-Hydroxynonenal induc es p53-mediated apoptosis in retinal pigment epithelial cells. Arch Biochem Biophys 2008; 480: 85-94.

37. Pettazzoni P, Ciamporcero E, Medana C, et al. Nuclear factor erythroid 2-related factor-2 activity controls 4-hydroxynonenal metabo lism and activity in prostate cancer cells. Free Radic Biol Med 2011; 51: 1610-8.

38. Yang Y, Sharma A, Sharma R, Patrick B, Singhal SS, Zimniak P, Awasthi S, Awasthi YC. Cells preconditioned with mild, transient UVA irradiation acquire resistance to oxidative stress and UVA-induced apoptosis: role of 4-hydroxynonenal in UVA-mediated signaling for apoptosis. J Biol Chem 2003; 278: 41380-8.

39. Cheng JZ, Sharma R, Yang Y, et al. Accelerated metabolism and exclusion of 4-hydroxynonenal through induction of RLIP76 and hGST5.8 is an early adaptive response of cells to heat and oxidative stress. J Biol Chem 2001; 276: 41213-23.

40. Sharma R, Sharma A, Dwivedi S, Zimniak P, Awasthi S, Awasth YC. 4-Hydroxynonenal self-limits fas-mediated DISC-independent apoptosis by promoting export of Daxx from the nucleus to the cytosol and its binding to Fas. Biochem 2008; 47: 143-56.

\section{Address for correspondence}

Zhi-Gang Cao

Urology Surgery, Nanjing First Hospital

Nanjing Medical University

e-mail: caozhigang11@sina.com

Submitted: 29.07 .2013

Accepted: 7.08.2013 